\title{
Exchange rate accommodation and inflation persistence in Europe: 1970-1998
}

Citation for published version (APA):

Kool, C. J. M., \& Lammertsma, A. (1999). Exchange rate accommodation and inflation persistence in Europe: 1970-1998. METEOR, Maastricht University School of Business and Economics. METEOR Research Memorandum No. 005 https://doi.org/10.26481/umamet.1999005

Document status and date:

Published: 01/01/1999

DOI:

10.26481/umamet.1999005

Document Version:

Publisher's PDF, also known as Version of record

\section{Please check the document version of this publication:}

- A submitted manuscript is the version of the article upon submission and before peer-review. There can be important differences between the submitted version and the official published version of record.

People interested in the research are advised to contact the author for the final version of the publication, or visit the DOI to the publisher's website.

- The final author version and the galley proof are versions of the publication after peer review.

- The final published version features the final layout of the paper including the volume, issue and page numbers.

Link to publication

\footnotetext{
General rights rights.

- You may freely distribute the URL identifying the publication in the public portal. please follow below link for the End User Agreement:

www.umlib.nl/taverne-license

Take down policy

If you believe that this document breaches copyright please contact us at:

repository@maastrichtuniversity.nl

providing details and we will investigate your claim.
}

Copyright and moral rights for the publications made accessible in the public portal are retained by the authors and/or other copyright owners and it is a condition of accessing publications that users recognise and abide by the legal requirements associated with these

- Users may download and print one copy of any publication from the public portal for the purpose of private study or research.

- You may not further distribute the material or use it for any profit-making activity or commercial gain

If the publication is distributed under the terms of Article $25 \mathrm{fa}$ of the Dutch Copyright Act, indicated by the "Taverne" license above, 


\title{
EXCHANGE RATE ACCOMMODATION AND INFLATION PERSISTENCE IN EUROPE: 1970-1998
}

Clemens J.M. Kool and Alex Lammertsma*

January 1999

\begin{abstract}
:
In this paper, we empirically investigate the link between exchange rate accommodation and inflation persistence in Europe. We extend and adjust the model proposed by Alogoskoufis and Smith (1991) to the case of a small open economy which manages its exchange rate to an (exogenously given) anchor country, Germany. According to the model, the first derivative of inflation persistence with respect to exchange rate accommodation is unambiguously positive. We propose to use the real exchange rate as an appropriate empirical proxy for the unobservable degree of exchange rate accommodation and estimate a non-linear autoregressive inflation equation for ten European countries (excluding Germany) for the period 1970:2-1998:2. Overall, we are unable to reject our starting hypothesis: lower exchange rate accommodation results in lower inflation persistence.
\end{abstract}




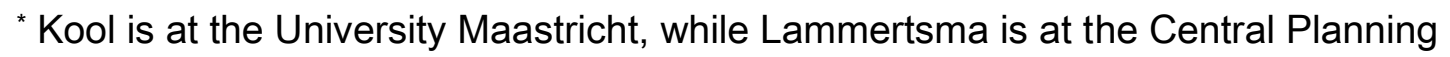
Bureau (CPB), the Hague, the Netherlands. The authors gratefully acknowledge fruitful discussions and comments from Kees Koedijk, Joan Muysken and participants of seminars at the University Maastricht and the University of Bonn, Germany. The views expressed are those of the individual authors and do not necessarily reflect the official position of the CPB. Any remaining errors are our own.

\section{Introduction}

Since the late 1970 's or early 1980 's, a major shift in monetary policy goals can be observed in most industrialized countries. The permanently high inflation in the preceding decade in combination with low economic growth significantly increased the general awareness of the costs of inflation. Also, a consensus gradually arose with respect to the limited role and effectiveness of macroeconomic demand management through monetary policy. Consequently, central banks increasingly opted for obtaining and subsequently maintaining low inflation or price stability as their primary policy goal.

To achieve this goal, central banks have used different strategies, such as explicit monetary targeting, exchange rate targeting relative to a low-inflation country, or in 
more recent years indirect inflation targeting. In general, these attempts have been successful. In almost all member countries of the EU inflation now is low and stable as opposed to the situation about twenty years ago. In Europe, the foundation of the European Monetary System (EMS) with the corresponding fixed Exchange Rate Mechanism (ERM) is generally assumed to have contributed to the decline in inflation'. Herz (1992), for instance claims that the ERM functioned as a D-mark zone where Germany took the role of the low-inflation anchor country. Other (high-inflation) countries then borrowed credibility to lower domestic price expectations in an attempt to increase their own reputation at relatively low costs².

A related but somewhat neglected issue in this respect is whether inflation persistence has changed over the past decades as well. Lower inflation persistence implies lower disinflation costs. Put differently, a rise inflation now is much harder to

1 See for an analysis of this development in the context of the European Monetary System Giavazzi and Pagano (1988), and Artis and Nachane (1990). In this literature, changing price expectations have a central position. Other (floating) non-ERM countries witnessed a similar inflation reduction, however, see De Grauwe (1990) for a comparative analysis.

2 See also De Grauwe (1991), Fratianni and von Hagen (1990), and Koedijk and Kool (1992) for an analysis of the D-mark zone hypothesis. 
undo in the future under high persistence than under low persistence. Therefore, the degree of persistence constrains current monetary policy.

Dornbusch (1982), Alogoskoufis and Smith (1991) -- henceforth AS (1991) -- and Algoskoufis (1992) develop theoretical models which show that inflation persistence is a function of the degree of monetary policy accommodation. ${ }^{3}$ AS (1991) and Algoskoufis (1992) use a symmetrical two-country model and distinguish between average (world) inflation persistence and relative inflation persistence. Average persistence is determined by money supply accommodation, while relative persistence is a function of exchange rate accommodation.

Obviously, the link between exchange rate accommodation and relative inflation persistence is the relevant case to consider for small open economies which fix (or manage) their exchange rate relative to a large anchor country. Also, the monetary history of Europe over the past three decades shows that the degree of exchange rate accommodation varies considerably over time and between countries. Especially the Southern-European high-inflation countries have been accommodating most of their cumulative inflation differentials with Germany until the mid or late eighties. Despite the presence of the ERM, exchange rates were adjustable through realignments rather than fixed. ERM-realignments became scarcer only after 1986, implying more strict

\footnotetext{
3 In Alogoskoufis (1992), price stickiness and persistence is based on staggered wage
} contracts, following Taylor (1979), for instance. AS (1991) base persistence on price adjustment costs, like Rotemberg (1982) and Mankiw (1985). Recently, Fuhrer and Moore (1995) provide an alternative model to explain persistence, which is based on relative wage considerations of private agents. 
adherence to the fixed-exchange rate constraint. The ERM crises of 1992 and 1993 and the widening of the ERM bands afterwards imply an increase in accommodation.

Despite the importance of the issue, empirical evidence on changes in the degree of (relative) inflation persistence is mostly lacking. To our knowledge, Anderton (1997) is the only example of such analysis. Anderton reports evidence which is generally -though not completely -- supportive of a decrease in inflation persistence in the 1980's relative to the 1970's. However, Anderton does not explicitly link the empirically observed degree of persistence to changes in accommodation over his sample, as suggested by the theoretical framework. Moreover, his analysis ends in the third quarter of 1992 to avoid problems associated with the ERM crises and the ensuing potential regime change.

In this paper, our purpose is first to extend and adjust the AS (1991) model to the case of a small open economy which manages its exchange rate to an (exogenously given) anchor country. Moreover, in the original model of AS (1991), the sign of the effect of changes in exchange rate accommodation to changes in (relative) inflation persistence is ambiguous. We augment the model with an equation which captures the expected long-run mean-reversion of the real exchange rate. Due to this extension, the first derivative of persistence with respect to exchange rate accommodation becomes unambiguously positive ${ }^{4}$. Second, we propose to use the level of the real exchange rate

\footnotetext{
${ }^{4}$ See Kool and Lammertsma (1997) for an exposition and elaboration of this effect.
} 
as an appropriate empirical proxy for the unobservable degree of exchange rate accommodation. Third, we specify and estimate a non-linear autoregressive inflation equation for ten European countries (excluding Germany) for the period 1970:2-1998:3. The (non-linear) use of the real exchange rate in the inflation equation avoids the need to arbitrarily choose structural break-points and allows for a continuous estimate of inflation persistence over the sample period.

Clearly, the analysis then is based on the joint hypothesis of the appropriateness of the level of the real exchange rate as a proxy for exchange rate accommodation in Europe and of the validity of the theoretical model. Our results provide overall supportive evidence for the existence of a positive link between exchange rate accommodation and inflation persistence. For most countries, persistence was reduced during the eighties, but increased again after 1992, suggesting an increased degree of short-run inflation independence for European countries relative to Germany.

The paper is set up as follows. In section 2, we present the extended and adjusted small-country version of the original AS (1991) theoretical model and derive the effect of accommodation on inflation persistence. In section 3, we discuss the data and present the empirical specification. In section 4 the results are presented, while summary and conclusions are in section 5 .

\section{The theoretical link between accommodation and persistence}


In this section, we provide the theoretical model underlying our empirical analysis. We take AS (1991) as our starting point. Whereas they use a symmetrical two-country model, we use a small economy variant, where the anchor country (Germany) is taken to be exogenous. In the AS (1991) framework, the direction of the effect of exchange rate accommodation on inflation persistence is ambiguous. Kool and Lammertsma (1997) show that the ambiguity is ultimately due to the assumption that the level of the real exchange rate is non-stationary. Although the debate on the validity of Purchasing Power Parity -- and consequent stationarity of the real exchange rate -- has not been decisively settled, considerable empirical evidence exists to support the long-run stationarity of real exchange rates 5 . Therefore, we introduce this stylized fact explicitly in our model ${ }^{6}$. It will be shown that the link between exchange rate accommodation and inflation persistence then becomes strictly positive.

The model presented here is a standard demand-supply aggregate model with price-setting firms for a small open economy. For convenience we assume the exogenous foreign log price level $p^{*}$ and foreign interest rate $i^{*}$ to be zero in the

${ }^{5}$ Rogoff (1996) offers a balanced overview. Recent evidence in support of long-run PPP may be found in Lothian (1997), Lothian and Taylor (1997) and Koedijk, Schotman and van Dijk (1998).

6 The hypothesized mean-reversion of the real exchange rate is based on the notion that (semi-)persistent real shocks which would affect the long-run real exchange rate level generally are scarce. Then, monetary (policy) shocks dominate real exchange rate behavior both in the short and the long run. 
theoretical model. Equation (1) represents the equilibrium in the domestic goods market (IS-curve), where the logarithm of aggregate demand $(y)$ depends on the real interest rate and real exchange rate respectively. iequals the nominal interest rate, while $p$ is the logarithm of the domestic price level and $e$ is the log nominal exchange rate. $v$ is a demand shock. Equation (2) is interest rate parity, reflecting perfect capital mobility, while equation (3) characterizes the exchange rate regime followed by the monetary authorities. The authorities accommodate a fraction $\varphi$ of deviations between the domestic and foreign log price level through exchange rate devaluation. Note that no explicit money demand equation is required, as it only serves to pin down the domestic money supply, given the monetary authorities' reaction function (3).

$y_{t}=-\alpha\left(i_{t}-E_{t}\left[p_{t+1}\right]+p_{t}\right)+\beta\left(e_{t}-p_{t}\right)+$ ypsilon $_{t}$

$i_{t}=E_{t}\left[e_{t+1}\right]-e_{t}$

$e_{t}=\phi p_{t}$

Equations (4)-(6) represent the supply side of the economy. The second order difference equation in the log of the domestic price level (equation (4)) is derived from the assumption of the existence of a large number of monopolistically competitive firms. Each firm is forward-looking and sets its price by minimizing an intertemporal loss function which penalizes both price deviations from the optimal price and price changes, due to for instance menu costs. Here $\lambda$ is the discount factor and $\theta$ measures the marginal cost of price adjustment versus the marginal cost of maintaining suboptimal prices. $q$ is the log of labor productivity, $w$ is the log of nominal wages, $v$ represents the 
mark-up factor in prices and $\pi$ is the optimal rate of price adjustment ${ }^{7}$. In equation (5), wage setters are forward looking and base their wages both on expected consumer prices and labor market conditions as measured by unemployment. _ is the exogenous supply of labor and /is actual labor demanded. $\omega$ is the target reservation wage. Finally, equation (6) reflects the assumption that output is proportional to labor, given exogenous labor productivity.

$$
\begin{aligned}
& E_{t}\left[p_{t+1}\right]=\left(\frac{1+\theta(1+\lambda)}{\lambda \theta}\right) p_{t}-\frac{1}{\lambda} p_{t-1}-\frac{1}{\lambda \theta}\left(v+w_{t}-q_{t}\right)-\frac{1-\lambda}{\lambda} \pi \\
& w_{t}=E_{t-1}\left[\delta p_{t}+(1-\delta) e_{t}\right]-\varepsilon E_{t-1}\left[\bar{n}-l_{t}\right]+\omega_{t} \\
& l_{t}=y_{t}-q_{t}
\end{aligned}
$$

Equation (7) extends the original AS (1991) model to include the expected meanreversion of real exchange rates. er symbolizes the log real exchange rate. For simplicity, we assume that the long-run logarithmic real exchange rate equals zero.

$$
E_{t}\left[e r_{t+1}\right]=\mu e r_{t}
$$

The solution to equations (1)-(7) can be easily found by a process of substitution. The resulting expression for the domestic price level is:

\footnotetext{
7 We refer to AS (1991) and Lammertsma (1997) for a more complete derivation and
} discussion. 


$$
\begin{gathered}
E_{t-1}\left[p_{t+1}\right]-\left(1+\frac{1+\theta-(\delta+(1-\delta) \phi)+\varepsilon(1-\phi)[\alpha(1-\mu)+\beta]}{\lambda \theta}\right) E_{t-1}\left[p_{t}\right]+\frac{1}{\lambda} p_{t-1}= \\
\frac{1}{\lambda \theta} E_{t-1}\left[z_{t}\right]
\end{gathered}
$$

where

$z_{t}=\varepsilon \bar{n}+(\varepsilon-1) q_{t}-\omega_{t}+v-\theta(1-\lambda) \pi$

Following AS (1991), equation (8) can be rewritten as

$\left(F^{2}-\left(\rho_{1}+\rho_{2}\right) F+\rho_{1} \rho_{2}\right) L E_{t-1}\left[p_{t}\right]=\frac{1}{\theta} \rho_{1} \rho_{2} E_{t-1}\left[z_{t}\right]$

where $\left(\rho_{1}+\rho_{2}\right)$ equals the coefficient of $E_{t-1}\left[p_{t}\right]$ in equation (8), and $\rho_{1} \rho_{2}$ equals $1 / \lambda$, the coefficient of $p_{t-1}$ in (8). $F$ and $L$ are the forward and backward shift operators respectively, and $\rho_{1}$ and $\rho_{2}$ are the two roots of the difference equation (8). Both roots are positive and they lay on either side of unity. Under the assumption that $\rho_{1}$ is the smaller root, equation (10) results in

$E_{t-1}\left[\Delta p_{t}\right]=\rho_{1} \Delta p_{t-1}+\frac{\rho_{1} \rho_{2}}{\theta\left(F-\rho_{2}\right)} E_{t-1}\left[z_{t}\right]$

Under the assumption that the stochastic elements in $z--$ that is $q$ and $\omega$-- are random walks with drift, the last term on the right-hand side of equation (11) is well-behaved and stationary. Consequently, inflation follows an $A R(1)$ process with autoregressive parameter $\rho_{1}$. This latter parameter characterizes the persistence of inflation and is an implicit function of the accommodation parameter $\varphi$. To derive the impact of $\varphi$ on $\rho_{1}$ note 
that the characteristic equation of the second-order difference equation on the lefthandside of equation (8) equals:

$z^{2}+b z+c$, where $b=-\left(\rho_{1}+\rho_{2}\right), c=\rho_{1} \rho_{2}$

Then,

$\rho_{1}=-\frac{1}{2}\left[b+\left(b^{2}-4 c\right)^{1 / 2}\right]$

and

$$
\begin{aligned}
& \frac{\partial \rho_{1}}{\partial \phi}=-\frac{1}{2}\left[1+b\left(b^{2}-4 c\right)^{-1 / 2}\right] \frac{\partial b}{\partial \phi}+\left(b^{2}-4 c\right)^{-1 / 2} \frac{\partial c}{\partial \phi} \\
& =-\frac{1}{2} \frac{\left[1+b\left(b^{2}-4 c\right)^{-1 / 2}\right]}{\lambda \theta}[(1-\delta)+\varepsilon(\alpha(1-\mu)+\beta)]
\end{aligned}
$$

Since the expression $\left[1+b\left(b^{2}-4 c\right)^{-1 / 2}\right]$ is negative by definition, the derivative in equation (14) is unambiguously positive as long as $\mu$ is smaller than 1 , that is as long as the real exchange rate is mean-reverting. This theoretical result will be the null hypothesis to be tested in the subsequent empirical work 8 .

8 Note that only countries which have adhered to some sort of exchange rate management are included in our analysis. For large -- and possibly more closed -- economies whose monetary policy preferences are mainly domestically determined, it is not exchange rate accommodation which affects inflation persistence, but domestic monetary accommodation. This would likely be the case for the US, Japan and Germany. 


\section{Data and model specification}

In the empirical analysis, we consider inflation persistence in ten European countries relative to Germany. These countries are Austria (au), Belgium (bg), Denmark (dk), France (fr), Ireland (ir), Italy (it), the Netherlands (nl), Portugal (pt), Spain (sp), and the United Kingdom (uk). Out of the current fifteen members of the European Union, Luxembourg has been excluded because of its monetary union with Belgium, Greece for data problems and Sweden and Finland for their only recent entry in the EU. Austria on the other hand is included because of its explicit though unilateral D-mark peg over the past decades. Obviously, the above countries differ substantially both in size, openness, economic autonomy and actual exchange rate policy. On the one extreme, the Netherlands and Austria are small open economies neighboring Germany, which have maintained an almost perfect peg to the D-mark since the late seventies. On the other extreme, the United Kingdom is larger, less focused on continental Europe in terms of trade and more autonomous in policy matters. It has switched between episodes of almost pure floating and periods of D-mark shadowing. Consequently, the data allows for a comparison of widely differing degrees of exchange rate accommodation both between countries and over time per country. 


\subsection{Data}

For all countries plus Germany, quarterly CPI-series have been obtained from the IFSdatabase (line 64) through DATASTREAM for the period 1969-1998. For Ireland, the incomplete IFS-series has been updated using the series from the Irish Statistical Office. Subsequently, the CPI series have been used to compute quarter-to-quarter (logarithmic) inflation for each country9 .

End-of-quarter exchange rates relative to the US dollar have been extracted from the same IFS-database (line ae). For the analysis, all US dollar exchange rates have been converted into D-mark exchange rates. The logarithm of each country's real exchange rate (er) relative to Germany will play a central role in the analysis as it proxies for exchange rate accommodation. Empirically, it is defined as the logarithm of $\left[E^{*} P_{G} / P\right]$ where $\mathrm{E}$ is the amount of currency units $i$ per D-mark and $P_{G}$ and $P_{i}$ are the price index of Germany and country i respectively ${ }^{10}$.

${ }^{9}$ Anderton (1997) computes inflation as the change in the log of the CPI relative to the same quarter in the previous year. This generates an overlapping data series with an MA(3) pattern.

10 The empirical definition of the real exchange rate is more general than that used in the theoretical derivation, as the German benchmark price level is allowed to change as well. 


\subsection{Model Specification}

The empirical counterpart of equation (11) should have the following general form: $\pi_{t}=c+\alpha(\phi) \pi_{t-1}+u_{t}$

where $\pi$ is inflation and $u$ represents the error term. According to the theoretical framework, the persistence parameter $\alpha$ is a function of the degree of accommodation $\varphi$. This raises the issue of measuring actual accommodation.

Anderton (1997) circumvents this problem. He disregards the dependency of $\alpha$ on $\varphi$ and estimates an equation similar to (15) over sub-periods. For each sub-period, $\alpha$ is a constant. However, $\alpha$ may change across sub-periods ${ }^{11}$. Anderton then compares $\alpha$ estimates across sub-periods and concludes that persistence significantly changes across sub-periods. The timing of structural breaks in persistence is assumed to coincide with the often used breaking points in the history of European exchange rate policy, like the founding of the ERM in the first quarter of 1979 and the increased discipline in the ERM in late 1982 or early 1983. Anderton fails to provide evidence on whether the chosen break points signal changes in actual accommodation. Moreover, the theoretical framework suggests that the link between accommodation and persistence is continuous rather than discrete.

Here, we propose a different approach, using a well-known characteristic of the ERM. Whenever European high-inflation countries in the past chose to fix their

\footnotetext{
11 In fact, this is the same approach AS (1991) follow when empirically comparing fixed and floating exchange rate regimes from 1862 to 1987 for the United States and the United Kingdom.
} 
exchange rate to the D-mark in the ERM, they faced a gradual real appreciation. As long as they refused to accommodate the inflation differential with Germany, their real exchange rate fell. A devaluation on the other hand to accommodate the accumulated inflation differential, would cause a real depreciation and a (temporary) gain in competitiveness. Obviously, the (logarithmic) level of the real exchange rate relative to its mean -- which is defined as er -- then provides a straightforward and continuous measure of the accumulated degree of past accommodation. In this paper, we exploit this property of the real exchange rate and include it non-linearly in equation (15). This leads to the following specification ${ }^{12}$ :

$\pi_{t}=c+\left(\alpha_{0} e r_{t-1}+\alpha_{1}\right) \pi_{t-1}+u_{t}$

Persistence then is measured by the expression $\left(\alpha_{1}+\alpha_{0} e r_{t-1}\right)$. Since quarterly inflation series have more complicated dynamics than the $A R(1)$ of equation (16), we include lags up till the fourth quarter. The final regression specification becomes:

$\pi_{t}=c+\alpha_{1} \pi_{t-1}+\alpha_{2} \pi_{t-2}+\alpha_{3} \pi_{t-3}+\alpha_{4} \pi_{t-4}+\alpha_{0} e r_{t-1} \pi_{t-1}+u_{t}$

with persistence being defined as $\left(\alpha_{1}+\alpha_{2}+\alpha_{3}+\alpha_{4}+\alpha_{0} e r_{t-1}\right)$. Two versions of equation (17)

will be estimated in section 4 . In the first one, we focus on domestic inflation in each of the countries as dependent variable, while in the second variant the inflation difference

12 The above non-linear specification is reminiscent of though not strictly comparable to the approach taken in the smooth transition autoregressive modeling literature. See, for instance, Lin and Teräsvirta (1994) and Eitrheim and Teräsvirta (1996). 
with Germany is taken to be the dependent variable. The first version most closely matches the assumption of exogenous and stable inflation and inflation persistence in Germany. In the second one, we relax this assumption and take possible variation in Germany's inflation into account as well.

\section{Results}

As a first step in the analysis, we provide supportive evidence on the two assumptions underlying the regression in equation (17). The first of these assumptions is the stationarity of inflation -- or the inflation differential with Germany for that matter --, which follows from the theoretical model. According to the derivation in equations (9)-(14), $\rho_{1}$ should be lower than unity, which implies a stationary inflation process. Second, we have augmented the original AS (1991) theoretical model with equation (7) which reflects expected mean-reversion in the log of the real exchange rate. As a consequence, persistence becomes unambiguously positively related to the level of exchange rate accommodation. With nonstationary real exchange rates, the direction of the accommodation effect on persistence become ambiguous and tests become harder to interpret. For this reason, stationarity (mean-reversion) of the logarithmic real exchange rate should be a stylized fact of the data. Moreover, in case the logarithmic real 
exchange rate would be nonstationary, equation (17) would contain a nonstationary explanatory variable and coefficient $\alpha_{0}$ would be biased towards zero.

In table 1 we summarize the evidence on the basis of our sample for the period 1969-1998. Phillips-Perron unit root tests are used to capture general dynamics of the disturbance term. For inflation and inflation differentials relative to Germany, the specification includes four lags, an intercept and trend. For the logarithmic level of the real exchange rate in deviation of its mean, results are reported for a specification with four lags, excluding an intercept and trend ${ }^{13}$. The evidence clearly supports the stationarity of both inflation per country and the inflation differential between each country and Germany over the sample. The evidence on the stationarity of the log level of the real exchange rate is less strong, though generally positive as well. Only for Austria and Ireland, a unit root cannot be rejected at the $10 \%$ level. However, especially in view of the long lags in mean reversion generally found in the literature on the one hand and the low power of unit root tests on the other, we feel justified in interpreting our results as generally supportive of mean-reversion of real exchange rates. In the remainder we will use this as a maintained hypothesis.

In table 2 we present the regression results of country-wise estimation of equation (17). Insignificant lags have been deleted. White's heteroskedasticity-consistent

13 In the more extended specification including a trend and intercept, both were generally insignificant for the real exchange rate. For Denmark and Portugal a marginally significant trend term was found. Remember er has a zero mean by construction. 
standard errors have been used to compute t-values. The latter are reported in the table in parentheses below the coefficient estimates. For each country the fit and regression characteristics are acceptable. Note though that it is not the purpose of fitting an optimal forecasting function for inflation. The coefficient $\alpha_{0}$ which is associated with the nonlinear accommodation term is always positive and significantly so at the 5 percent level for Austria, Denmark, the Netherlands, Portugal, and the United Kingdom. For Belgium, Ireland, Italy and Spain marginal significance around the 10 percent level is realized. Only for France, the resulting coefficient is insignificant. Overall, we conclude that our results lend credibility to the joint hypothesis of (i) exchange rate accommodation being appropriately measured by the level of the real exchange rate and (ii) inflation persistence being positively dependent on the level of accommodation ${ }^{14}$.

So far, each equation has been estimated separately. Now, we re-estimate the country-specific regressions simultaneously using SUR. The results remain qualitatively similar in terms of inflation dynamics. However, the significance of the non-linear term increases considerably for most countries. To save space, table 3 only reports the $\alpha_{0}$ coefficients with the associated t-value for each country found under SUR-estimation for the period 1970:2-1998:3. Now only for Italy an insignificant coefficient is reported, while

\footnotetext{
${ }^{14}$ As an additional exercise, we replaced the non-linear term $\alpha_{0} e r_{t-1} \pi t_{-1}$ in equation (17) by the term $\alpha_{o}\left(e r_{t-1}+e r_{t-2}+e r_{t-3}+e r_{t-4}\right) \pi_{t-1}$. Since the results are qualitatively similar, they remain unreported. However, they are available from the author on request.
} 
for France marginal significance is gained. In all other countries, the accommodation effect on persistence is significantly positive.

Finally, we observe that a Wald-test on the equality of $\alpha_{0}$ across Belgium, Denmark and the Netherlands can not be rejected. Neither can the restriction of equality of $\alpha_{0}$ for all other countries be rejected ${ }^{15}$. Re-estimating the SUR-system under these restrictions again leaves the inflation dynamics roughly unaffected. In table 4, we report the $\alpha_{0}$-estimates for Belgium, Denmark and the Netherlands on the one hand and the remaining countries on the other. For both groups of countries, the coefficient is strongly significant. For the three small countries neighboring Germany, the impact of accommodation on inflation persistence is certainly stronger than for the other countries.

In table 5, we report results for inflation differential regressions in a similar form as table 2. The analysis is repeated here for each country's inflation differential relative to Germany. The evidence corroborates out earlier findings. Again a strictly positive effect of accommodation on inflation persistence is found, which is insignificant for France and the Netherlands only. Especially for Belgium, Italy and Spain, the size and significance of $\alpha_{0}$ increases considerably.

For a more detailed view on the development of persistence across time, we use the results from table 2 to compute a time series of inflation persistence for each

\footnotetext{
${ }^{15}$ Austria in fact is an intermediate case. Inclusion in the group of Belgium, the Netherlands
} and Denmark is clearly rejected. Its inclusion into the other group formally cannot be rejected, although it is a borderline case. Nevertheless, it is a sort of outlier in that group too. 
country; the series are presented in figure 1. Obviously, persistence which has been earlier defined as $\left(\alpha_{1}+\alpha_{2}+\alpha_{3}+\alpha_{4}+\alpha_{0} q_{t-1}\right)$ is a linear function of a country's logarithmic real exchange rate with respect to Germany.

According to the time paths displayed in figure 1, the dynamics of inflation persistence have been more complex, heterogeneous and time-varying than suggested by the simple break-point analysis of Anderton. On the other hand, the period 1979-1983 for many countries indeed is one in which dramatic changes in inflation persistence have taken place. Also, we confirm Anderton's conclusion that countries generally experienced a downward shift in persistence in the early eighties as compared to the seventies for Austria, Denmark, Ireland, the United Kingdom, Spain (actually more the late seventies), Italy, and to a lesser extent the Netherlands.

However, our results allow a more precise discussion of the experience in individual countries. Necessarily, such discussion is less formal and more speculative in nature. In our view, it is nevertheless valuable as it allows for a more economic approach to evaluate the plausibility of the results.

First, persistence in France has been oscillating approximately around a stationary level of about 0.9 over the whole sample. This explains the insignificance of $\alpha_{0}$ in our regressions for France. Economically, it implies that the French-German real exchange rate has been more or less constant. In view of the persistent -- though declining -- inflation differential between these two countries over the whole sample, it suggests that France generally implemented its own domestic monetary policy and kept 
its exchange rate aligned with realized inflation differentials. As a corollary, it means that the convergence of French to German inflation over the past decade has not been achieved primarily by lower exchange rate accommodation but by lower monetary accommodation at home. If true, French inflation persistence should be modeled as a function of domestic monetary accommodation rather than as a function of exchange rate accommodation.

Second, all of Germany's small neighbors -- Belgium, Denmark, the Netherlands, and Austria -- experience a downward shift in inflation persistence as early as the mid1970's. Speculatively, one might argue that participation in the so-called "snakearrangement" that was set up after the demise of the Bretton Woods system is underlying this feature for the first three countries. From 1974 onward, Austria gave absolute priority to the unilateral peg of the schilling to the D-mark, see Kool (1995).

Third, the United Kingdom and Ireland both experienced a significant downward shift in persistence around 1980. As for France, one might question the appropriateness of modeling UK inflation persistence as a function of exchange rate accommodation rather than domestic monetary accommodation. In fact, the UK formally floated against the D-mark in the late seventies and early eighties and initiated a disinflation on its own in this period through tight domestic monetary policy. However, Bean (1988) argues that the implemented monetary contraction explains approximately half of the observed real 
appreciation of the pound against other currencies in this period ${ }^{16}$. In that respect, the decline in persistence may be correctly captured by our exchange-rate-based accommodation measure even when caused by a monetary contraction at home. For the case of Ireland, two possibly complementary explanations can be offered for the decline in persistence in the early 1980's. On the one hand, entry in the ERM in 1979 may have contributed to the observed downward shift in persistence -- similar to what happened in Italy around that time for instance. On the other hand, the United Kingdom and Ireland were closely connected up till that point through the one-to-one currency peg. Also, bilateral trade with the UK was a dominant characteristic for the Irish economy. In combination, these two factors may have led to a spill-over effect on Irish inflation persistence from the British monetary contraction as well.

Fourth, a number of the traditionally weak currency countries in the EMS show an additional decline in inflation persistence around the years 1985-1986. Anderton refers to this as the hardening of the ERM constraints. This includes Belgium, Denmark, and Italy. Even later, the same holds for Spain and Portugal around 1987. Both entered the ERM even later than that, but started shadowing the D-mark prior to entry.

Fifth, for almost all countries, inflation persistence increases after the 1992-1993 ERM crises, though with different degrees. Certainly, the increased fluctuation margins

16 Bean (1988) attributes the other half of the real exchange rate appreciation of the pound in the early 1980's to the discovery and exploitation of natural resources in British part of the North Sea. 
allow a larger degree of exchange rate accommodation and therefore of inflation independence. However, countries have used this increased freedom only to a limited extent in most cases. Alternatively, one could argue that the observed increase in inflation persistence in fact follows from the permanent shift in Germany's real exchange rate due to the German unification in 1990. The required real appreciation of the D-mark has been brought about mainly through persistently lower inflation in the rest of Europe, given the fixed exchange rate constraint. Since prices are sticky in the short run and only gradually adjust, the prolonged period of price adjustment may have led to a (semipermanent) increase in inflation persistence in most European countries during the transition.

\section{Summary and conclusions}

In most industrialized countries, inflation was high and rising in the seventies, declined in the eighties and stabilized at relatively low levels in the nineties. Since the early 1980's monetary policy became increasingly oriented at price stability. In Europe, the founding of the European Monetary System in 1979 and the functioning of the ERM since that time has contributed to the convergence of inflation in the participating countries to that of Germany, the low-inflation anchor country. Literature on this topic abounds. 
Strikingly, little attention has been paid empirically to the development of inflation persistence. Anderton (1997) is an exception. The issue deserves closer attention in our view, however. Since higher inflation persistence implies higher disinflation costs, the degree of persistence provides an important constraint on current monetary policy.

Attempts to develop theoretical models which link inflation persistence to monetary policy accommodation can be found in Dornbusch (1982), Alogoskoufis and Smith (1991) and Alogoskoufis (1992). In general, the literature distinguishes between domestic monetary accommodation through a money supply reaction function and exchange rate accommodation. Obviously, the latter case is important for small open economies which manage their exchange rate with respect to some anchor country.

In this paper, we start from the theoretical framework developed by Alogoskoufis and Smith (1991). Our purpose is first to adjust the AS (1991) symmetrical two-country model to the case of a small open economy which manages its exchange rate to an (exogenously given) anchor country. Also, we augment the model with an equation reflecting expected long-run mean-reversion of the real exchange rate. This makes the first derivative of persistence with respect to exchange rate accommodation unambiguously positive.

Second, we propose to use the level of the real exchange rate as an appropriate empirical proxy for the unobservable degree of exchange rate accommodation. Third, we specify and estimate a non-linear autoregressive inflation equation for ten European countries (excluding Germany) for the period 1970:2-1998:2. The (non-linear) use of the 
real exchange rate in the inflation equation avoids the need to arbitrarily choose structural break-points and allows for a continuous estimate of inflation persistence over the sample period. Clearly, our tests are for the joint hypothesis of the validity of the model and the appropriateness of our accommodation measure.

We then first report evidence based on unit-root tests in support of two assumptions underlying the analysis: the stationarity of inflation and of the level of the logarithmic real exchange rate. Subsequently, we show that a significantly positive relation exists between inflation persistence and exchange rate accommodation as measured by the log real exchange rate for a majority of the countries investigated individually. Estimating the inflation equations for all countries simultaneously even strengthens the results. Variations in the specification of the non-linear accommodation term or switching from inflation to inflation differentials with Germany as the dependent variable yields qualitatively similar results. Overall, we are unable to reject our starting hypothesis, that lower accommodation results in lower persistence.

In practice, the results point out that inflation persistence has been declining in the eighties for most countries, with an upward shift again after the early nineties. Experience differs substantially across countries, though. On the other hand, groups of countries may share specific patterns in inflation persistence across time. In section 4, we have made an attempt to link our empirical results to actual policy performance in various countries in a narrative way. Admittedly, such attempt is somewhat speculative 
in nature. Nevertheless, it clarifies the impact policy choices and preferences may have on inflation characteristics.

As a final caveat, we should mention that our results point at the possibility that monetary policy in especially France and the United Kingdom has been influenced by domestic priorities to such extent, that exchange rate accommodation for these countries may not have been the major determinant of inflation persistence. Possibly, money supply accommodation should have been taken into account. If so, they belong more to the category of the United States, Japan, and Germany than to that of the small European countries which follow Germany. However, the investigation of the effect of money supply accommodation on inflation persistence for countries with more policy autonomy is left for future research.

\section{References}

Alogoskoufis, G.S., "Monetary Accommodation, Exchange Rate Regimes and Inflation Persistence", The Economic Journal, May 1992, 102, 461-480.

Alogoskoufis, G.S. and R. Smith, "The Phillips Curve, the Persistence of Inflation, and the Lucas Critique: Evidence from Exchange-rate Regimes", The American Economic Review, December 1991, 81, 1254-1275.

Anderton, R., "Did the Underlying Behaviour of Inflation Change in the 1980s? A Study of 17 Countries", Weltwirtschaftliches Archiv, 1997, 133, 22-38.

Artis, M., and D. Nachane, "Wages and Prices in Europe: A Test of the German Leadership Hypothesis", Weltwirtschaftliches Archiv, 1990, 126, 59-77.

Bean, C.R., "Sterling Misalignment and British Trade Performance (with comments)", in R.C. Marston (ed.), Misalignment of Exchange Rates: Effects on Trade and Industry, 1988, 3976. 
De Grauwe, P., "The Cost of Disinflation and the European Monetary System", Open Economies Review, 1990, 1, 147-173.

De Grauwe, P., "Is the EMS a DM-Zone?", in A. Steinherr and D. Weiserbs (eds.): Evolution of the International and Regional Monetary Systems, London: Macmillan, 1991.

Dornbusch, R., "PPP Exchange-Rate Rules and Macroeconomic Stability”, Journal of Political Economy, February 1982, 90, 158-165.

Eitrheim, $\varnothing$, and T. Teräsvirta, "Testing the Adequacy of Smooth Transition Autoregressive Models", Journal of Econometrics, 1996, 74, 59-75.

Fratianni, M., and J. von Hagen, "German Dominance in the EMS: The Empirical Evidence", Open Economies Review, 1990, 1, 86-107.

Fuhrer, J., and G. Moore, “Inflation persistence”, The Quarterly Journal of Economics, February $1995,110,127-159$.

Giavazzi, F., and M. Pagano, “The Advantage of Tying One's Hands: EMS Discipline and Central Bank Credibility", European Economic Review, 1988, 32, 1055-1082.

Herz, B., and W. Roger, "The EMS is a Greater Deutsch-Mark Area", European Economic Review, October 1992, 36, 1413.1425.

Koedijk, C.G., and C.J.M. Kool, "Dominant Interest and Inflation Differentials within the EMS", European Economic Review, May, 1992, 36, 925-943.

Koedijk, C.G., P. Schotman, and M.A. van Dijk, "The Re-emergence of PPP in the 1990s", Journal of International Money and Finance, February 1998, 17, 51-61.

Kool, C.J.M., "Monetary Policy Under Fixed Exchange Rates: Lessons from the Netherlands, Belgium, and Austria, 1973-1992”, De Economist, August 1995, 143, 329-351.

Kool, C.J.M., and A. Lammertsma, "The Phillips Curve, the Persistence of Inflation and the Lucas Critique: Evidence from Exchange-Rate Regimes: Comment", METEOR research memorandum 97/041, 1997, 1-7.

Lammertsma, Alex, "Inflation-Output Trade-Offs and the Implications for Monetary Policy", 1997, University Press Maastricht, chapters 5 and 6.

Lin, C., and T. Teräsvirta, "Testing the Constancy of Regressions Parameters against Continuous Structural Change”, Journal of Econometrics, 1994, 62, 211-228.

Lothian, J.B., "Multi-Country Evidence on the Behavior of Purchasing Power Parity under the Current Float", Journal of International Money and Finance, February 1997, 16, 19-35. 
Lothian, J.B, and M.P. Taylor, "Real Exchange Rate Behavior”, Journal of International Money and Finance, December 1997, 16, 745-754.

Mankiw, N.G., "Small Menu Costs and Large Business Cycles: A Macroeconomic Model of Monopoly”, The Quarterly Journal of Economics, May 1985, 100, 529-539.

Rogoff, K., "The Purchasing Power Parity Puzzle”, Journal of Economic Literature, $1996,34,647-668$.

Rotemberg, J.J., "Sticky Prices in the United States", Journal of Political Economy, $1982,90,1187-1211$.

Taylor, J.B., "Staggered Wage Setting in a Macro Model”, American Economic Review, $1979,69,108-113$. 
Table $1 \quad$ Unit root tests 1969:3-1998:2 (Phillips-Perron)

\begin{tabular}{|l|c|c|c|c|c|c|c|c|c|c|}
\hline & $\mathrm{au}$ & $\mathrm{bg}$ & $\mathrm{dk}$ & $\mathrm{fr}$ & $\mathrm{ir}$ & $\mathrm{it}$ & $\mathrm{nl}$ & $\mathrm{pt}$ & $\mathrm{sp}$ & $\mathrm{uk}$ \\
\hline$\pi$ & 12.04 & 5.43 & 9.48 & 3.77 & 7.34 & 4.07 & 9.11 & 6.68 & 7.28 & 7.51 \\
\hline$\pi-\pi g e$ & 13.17 & 6.82 & 10.18 & 5.94 & 7.85 & 4.78 & 12.54 & 6.53 & 7.27 & 8.14 \\
\hline$e r$ & 1.32 & 2.45 & 1.88 & 3.58 & 1.57 & 2.16 & 2.3 & 2.1 & 2.05 & 2.05 \\
\hline
\end{tabular}

Note: Entries in the table are (absolute values of) t-statistics to test for a unit root. In the rows for inflation and inflation differentials, the specification includes 4 lags, an intercept and a trend. Critical values are $4.04(1 \%), 3.45(5 \%)$, and $3.15(10 \%)$. In the bottom row for the real exchange rate level, the specification includes 4 lags, but excludes a trend and intercept. Critical values are $2.58(1 \%), 1.94(5 \%)$, and $1.62(10 \%)$.

Table 2 Inflation regressions 1970:2-1998:2

$\pi_{t}=c+\alpha_{1} \pi_{t-1}+\alpha_{2} \pi_{t-2}+\alpha_{3} \pi_{t-3}+\alpha_{4} \pi_{t-4}+\alpha_{0} \pi_{t-1}{ }^{*} e r_{t-1}+u_{t}$

\begin{tabular}{|l|c|c|c|c|c|c|c|c|c|c|}
\hline & $\mathrm{au}$ & $\mathrm{bg}$ & $\mathrm{dk}$ & $\mathrm{fr}$ & $\mathrm{ir}$ & $\mathrm{it}$ & $\mathrm{nl}$ & $\mathrm{pt}$ & $\mathrm{sp}$ & $\mathrm{uk}$ \\
\hline interce & 1.25 & 0.41 & 2.10 & 0.37 & 1.18 & 2.30 & 0.51 & 3.96 & 1.18 & 1.88 \\
$\mathrm{pt}$ & $(4.19$ & $(1.27$ & $(3.91$ & $(1.39$ & $(1.96$ & $(3.72$ & $(1.40$ & $(3.75$ & $(1.53$ & $(2.38$ \\
& ) & ) & ) & ) & ) & ) & ) & ) & ) \\
\hline$\pi_{-1}$ & - & 0.37 & - & 0.60 & 0.18 & 0.72 & - & 0.28 & - & 0.26 \\
$(3.54$ & & $(6.74$ & $(1.66$ & $(9.35$ & & $(2.33$ & & $(3.16$ \\
& & ) & & ) & ) & & ) & & ) \\
\hline$\pi-2$ & - & 0.28 & 0.28 & - & & - & 0.30 & - & 0.23 & - \\
\hline
\end{tabular}




\begin{tabular}{|c|c|c|c|c|c|c|c|c|c|c|}
\hline & & $\begin{array}{c}(2.59 \\
)\end{array}$ & $\begin{array}{c}(2.22 \\
)\end{array}$ & & & & $\begin{array}{c}(3.49 \\
)\end{array}$ & & $\begin{array}{c}(1.87 \\
)\end{array}$ & \\
\hline$\pi_{-3}$ & - & - & - & $\begin{array}{c}0.32 \\
(3.44 \\
)\end{array}$ & $\begin{array}{c}0.29 \\
(3.12 \\
)\end{array}$ & - & - & - & $\begin{array}{c}0.33 \\
(3.47 \\
)\end{array}$ & - \\
\hline$\pi-4$ & $\begin{array}{c}0.62 \\
(8.90 \\
)\end{array}$ & $\begin{array}{c}0.26 \\
(2.84 \\
)\end{array}$ & $\begin{array}{c}0.29 \\
(2.52 \\
)\end{array}$ & - & $\begin{array}{c}0.33 \\
(3.29 \\
)\end{array}$ & - & $\begin{array}{c}0.56 \\
(8.85 \\
)\end{array}$ & $\begin{array}{c}0.36 \\
(4.22 \\
)\end{array}$ & $\begin{array}{c}0.29 \\
(3.15 \\
)\end{array}$ & $\begin{array}{c}0.47 \\
(4.67 \\
)\end{array}$ \\
\hline$\pi_{-1}{ }^{*} e r_{-1}$ & $\begin{array}{c}2.15 \\
(5.35 \\
)\end{array}$ & $\begin{array}{c}1.78 \\
(1.84 \\
)\end{array}$ & $\begin{array}{c}3.73 \\
(5.45 \\
)\end{array}$ & $\begin{array}{c}0.73 \\
(1.21 \\
)\end{array}$ & $\begin{array}{c}0.87 \\
(1.55 \\
)\end{array}$ & $\begin{array}{c}0.66 \\
(1.67 \\
)\end{array}$ & $\begin{array}{c}2.25 \\
(2.50 \\
)\end{array}$ & $\begin{array}{c}1.60 \\
(2.90 \\
)\end{array}$ & $\begin{array}{c}0.54 \\
(1.71 \\
)\end{array}$ & $\begin{array}{c}1.00 \\
(3.02 \\
)\end{array}$ \\
\hline $\operatorname{adj} R^{2}$ & 0.62 & 0.66 & 0.47 & 0.77 & 0.56 & 0.65 & 0.69 & 0.42 & 0.6 & 0.53 \\
\hline SEE & 2.05 & 2.04 & 3.47 & 1.99 & 4.74 & 3.58 & 1.9 & 7.32 & 3.86 & 4.4 \\
\hline
\end{tabular}

Note: t-values are reported below the coefficients in parentheses. 
Table $3 \quad$ Unrestricted SUR-estimation 1970:2-1998:2

\begin{tabular}{|c|c|c|c|c|c|c|c|c|c|c|}
\hline & $\mathrm{au}$ & $\mathrm{bg}$ & $\mathrm{dk}$ & $\mathrm{fr}$ & $\mathrm{ir}$ & $\mathrm{it}$ & $\mathrm{nl}$ & $\mathrm{pt}$ & $\mathrm{sp}$ & $\mathrm{uk}$ \\
\hline$\pi_{-1^{*} e r_{-1}}$ & 1.39 & 2.17 & 3.23 & 0.61 & 0.79 & 0.35 & 2.39 & 1.00 & 0.76 & 1.30 \\
{$\left[\alpha_{0}\right]$} & $(3.45$ & $(4.16$ & $(4.61$ & $(1.65$ & $(2.66$ & $(1.29$ & $(4.03$ & $(2.33$ & $(2.37$ & $(5.32$ \\
& ) & ) & ) & ) & ) & ) & ) & ) & ) & ) \\
\hline
\end{tabular}

Note: t-values are reported below the coefficients in parentheses.

Table $4 \quad$ Restricted SUR-estimation 1970:2-1998:2

\begin{tabular}{|c|c|c|}
\hline & $\mathrm{bg}=\mathrm{dk}=\mathrm{nl}$ & $\begin{array}{c}\mathrm{au}=\mathrm{fr}=\mathrm{ir}=\mathrm{it} \\
=\mathrm{pt}=\mathrm{sp}=\mathrm{uk}\end{array}$ \\
\hline$\pi_{-1}{ }^{*} \mathrm{r}_{-1}$ & 2.45 & 0.85 \\
{$\left[\alpha_{0}\right]$} & $(7.05)$ & $(6.46)$ \\
\hline
\end{tabular}

Note: $\mathrm{t}$-values are reported below the coefficients in parentheses.

Table 5 Inflation differential regressions 1970:2-1998:2

$\left(\pi-\pi^{g e}\right)_{t}=c+\alpha_{1}\left(\pi-\pi^{g e}\right)_{t-1}+\alpha_{2}\left(\pi-\pi^{g e}\right)_{t-2}+\alpha_{3}\left(\pi-\pi^{g e}\right)_{t-3}+\alpha_{4}\left(\pi-\pi^{g e}\right)_{t-4}+\alpha_{0}\left(\pi-\pi^{g e}\right)_{t-1}{ }^{*} e r_{t-1}+u_{t}$

\begin{tabular}{|l|c|c|c|c|c|c|c|c|c|c|}
\hline & $\mathrm{au}$ & $\mathrm{bg}$ & $\mathrm{dk}$ & $\mathrm{fr}$ & $\mathrm{ir}$ & $\mathrm{it}$ & $\mathrm{nl}$ & $\mathrm{pt}$ & $\mathrm{sp}$ & $\mathrm{uk}$ \\
\hline intercept & 0.29 & 0.26 & 1.04 & 0.28 & 0.90 & 1.29 & 0.26 & 3.48 & 1.47 & 1.36 \\
\hline$\left[\pi^{\left.-\pi^{g}\right]-1}\right.$ & $(1.49)$ & $(1.24)$ & $(2.40)$ & $(1.02)$ & $(2.19)$ & $(2.65)$ & $(1.28)$ & $(3.44)$ & $(2.85)$ & $(2.89)$ \\
\hline
\end{tabular}




\begin{tabular}{|l|c|c|c|c|c|c|c|c|c|c|}
\hline & & $(3.52)$ & & $(4.12)$ & $(1.86)$ & $(4.50)$ & & $(2.33)$ & & $(2.30)$ \\
\hline$\left[\pi-\pi^{g e}\right]_{-2}$ & - & - & - & - & - & - & - & 0.32 & - & 0.19 \\
\hline$\left[\pi-\pi^{g e}\right]_{-3}$ & - & - & - & - & 0.27 & - & - & - & 0.35 & -0.20 \\
\hline$\left[\pi-\pi^{g e}\right]_{-4}$ & 0.53 & 0.45 & 0.51 & 0.54 & 0.30 & 0.26 & 0.67 & - & 0.37 & 0.44 \\
\hline$\left[\pi-\pi^{g e}\right]_{-1}^{*} e r_{-1}$ & 2.31 & 5.10 & 3.84 & 1.63 & 0.96 & 1.17 & 2.49 & 1.46 & 0.83 & 1.54 \\
\hline SEE & $(6.18)$ & $(6.10)$ & $(5.50)$ & $(5.41)$ & $(3.33)$ & $(2.94)$ & $(8.99)$ & & $(4.93)$ & $(4.70)$ \\
\hline adj R & 2.1 & 2.16 & 3.87 & 2.4 & 4.5 & 3.57 & 2.09 & 7.24 & 4.24 & 3.88 \\
\hline
\end{tabular}

Note: $\mathrm{t}$-values are reported below the coefficients in parentheses. 